Research Paper

\title{
Adaptive response of single and binary Pseudomonas aeruginosa and Escherichia coli biofilms to benzalkonium chloride
}

\author{
Idalina Machado, Susana Patrícia Lopes, Ana Margarida Sousa, and Maria Olívia Pereira \\ IBB - Institute for Biotechnology and Bioengineering, Centre of Biological Engineering, University of Minho, \\ Campus de Gualtar, 4710-057 Braga, Portugal
}

The main goal of this work was to examine whether the continuous exposure of single and binary P. aeruginosa and E. coli biofilms to sub-lethal benzalkonium chloride (BC) doses can induce adaptive response of bacteria. Biofilms were formed during $24 \mathrm{~h}$ and then put continuously in contact with BC for more 5 days. The six-day-old adapted biofilms were then submitted to BC challenge, characterized and inspected by SEM. Both single and binary adapted biofilms have clearly more biomass, polysaccharides and proteins and less activity even though the number of cells was identical. After BC treatment, adapted biofilms maintained their mass and activity. SEM examination revealed that those adapted biofilms had a slimier and denser matrix that became thicker after BC treatment. Continuous exposure of bacteria to antimicrobials can lead to development of biofilms encompassing more virulent and tolerant bacteria. This adaptive resistance can be the result of a phenotypic adaptation, a genetic acquired resistance or both. Instead of eradicating biofilms and kill microorganisms, the use of a disinfectant can, favour biofilm formation and tolerance. This must be a genuine concern as it can happen in clinical environments, where the use of antimicrobials is unavoidable.

Keywords: Biofilms / Adaptive resistance / Benzalkonium chloride / Pseudomonas aeruginosa

Received: March 16, 2011; accepted: May 01, 2011

DOI 10.1002/jobm.201100137

\section{Introducton}

Pseudomonas aeruginosa and Escherichia coli are two of the most important human associated pathogens and commensal bacteria [1] that can contaminate inanimate surfaces during months, specially when attached and developing biofilms [2]. Both bacteria show an increase in pathogenicity due to their motility structures (type IV pili in P. aeruginosa and curli in E. coli) and matrix production through extracellular polymeric substances (EPS) secretion. Previous works [3-6] showed that EPS synthesis (alginate for P. aeruginosa and colanic acid in E. coli) is induced upon attachment of the bacteria to a surface.

Correspondence: Maria Olívia Pereira, IBB - Institute for Biotechnology and Bioengineering, Centre of Biological Engineering, Universidade do Minho, Campus de Gualtar, 4710-057 Braga, Portugal

E-mail: mopereira@deb.uminho.pt

Phone: +351 253604402

Fax: +351253678986
Usually, the procedures for surface cleaning involve the use of detergents followed by application of disinfectants that reduce the viability of microorganisms [7]. Antimicrobials, as quaternary ammonium compounds, have been continuously used in hospitals and healthcare facilities, and have significantly contributed to maintain sanitary conditions and to prevent hospitalacquired infections. Despite their valuable properties, concerns have been raised about the widespread and irrational use of disinfectants that could fail the eradication of the biofilm-associated microorganisms and serve to select disinfectant-insusceptible microbes among hospital-acquired pathogens [8-11].

Physiologic or phenotypic adaptation resulting in "antimicrobial tolerance" has been attributed to biofilms [12, 13]. Biofilm tolerance to disinfectants may result from (i) slow microbial growth rates that are attributable to nutrient depletion within biofilms, (ii) binding of the biocide to EPS, (iii) neutralization or 
degradation of the biocide, as well as (iv) the expression of biofilm-specific phenotypes [2, 12, 14]. There are evidences that proteins involved in oxidative stress response, cell envelope synthesis, and EPS synthesis are up-regulated in biofilms, indicating that these altered phenotypes might contribute to cell survival, persistence, and growth in a biofilm community $[15,16]$.

Moreover, biofilms usually comprise more than one microbial species, and can harbour strains with less ability to develop a biofilm, contributing to their survival and persistence. It has been reported that two bacteria present in an in vitro binary biofilm may live synergistically and enhance each other survival to antimicrobial treatments compared with the corresponding single species biofilms [17]. An important aspect of the study of the interactions in multispecies biofilms is to evaluate whether individual species, or the bacterial consortium, gain any fitness advantages compared to single-species biofilms. A fitness advantage in this context is defined as the ability of the organism or biofilm to persist or grow in a given environment or under a particular environmental stress. Multiple species biofilms may be thicker and more stable than the single ones, which may influence their susceptibility to disinfectants [18].

The aim of this work was to examine whether exposure of $P$. aeruginosa and E. coli to benzalkonium chloride $(\mathrm{BC})$ during single and binary biofilm formation, could induce an adaptive response in bacteria by evaluating the biofilms behaviour after treatment with the same agent. BC is a well-known quaternary ammonium compound (QAC) that has been widely used as surface disinfectant, antiseptic and preservative in medical arenas. Considering the intense use of $\mathrm{BC}$ as an antimicrobial agent, it is important to increase the knowledge about the effects of external chemical pressure and polimicrobial growth on the susceptibility of the sessile target organisms to this QAC.

\section{Materials and methods}

\section{Strain and culture conditions}

Pseudomonas aeruginosa ATCC 10145 and Escherichia coli K12 substrain MG 1655 were preserved in criovials (Nalgene) at $-80 \pm 2{ }^{\circ} \mathrm{C}$. Prior to each experiment, bacterial cells were grown on Tryptic Soy Agar (TSA, Merck) plates for $24 \mathrm{~h}$ at $37^{\circ} \mathrm{C}$.

To prepare the bacterial suspension, one colony of each bacterium (P. aeruginosa and E. coli) were collected from the TSA plates and grown in Tryptic Soy Broth (TSB) for $24 \mathrm{~h}$ at $37^{\circ} \mathrm{C}$, in a horizontal shaker (120 rpm).
Subsequently, bacteria were washed twice with ultrapure sterilized water (UP). Standardized cell suspensions were prepared in TSB at a cell density of $1 \times 10^{7}$ $\mathrm{cfu} / \mathrm{ml}$, unless otherwise stated.

\section{Antibacterial agent}

Benzalkonium Chloride (BC), a quaternary ammonium compound, with critical micellar concentration of $5.0 \mathrm{mM}$ was purchased from Calbiochem (Merck Biosciences, UK).

\section{Determination of minimum inhibitory concentration (MIC) and minimum bactericidal concentration (MBC)}

The MIC and MBC of BC of P. aeruginosa and E. coli were determined by the microdilution method according to Clinical and Laboratory Standards Institute (formerly NCCLS) [19].

Briefly, 96-well round-bottom microtiter plates (polystyrene, Orange, USA) with a total well capacity $300 \mu \mathrm{l}$ were used. In each well, $50 \mu 1$ of fresh TSB with increasing concentrations of $\mathrm{BC}$ were added to $50 \mu \mathrm{l}$ of each bacterial inoculum (containing approximately $\left.1 \times 10^{5} \mathrm{cfu} / \mathrm{ml}\right)$. The culture-plates were incubated at $37^{\circ} \mathrm{C}$ for $24 \mathrm{~h}$ in an orbital shaker at $120 \mathrm{rpm}$. The highest concentration of $\mathrm{BC}$ that did not promote growth was recorded as the MIC.

MBC determination was performed by transferring $10 \mu \mathrm{l}$ of culture from each well without visible growth into TSA plates. The lowest antimicrobial concentration that yielded no colony growth after $24 \mathrm{~h}$ at $37^{\circ} \mathrm{C}$ was documented as the MBC.

\section{Biofilm development and adaptation}

The methodology used to grow the bacterial biofilms was based on the microtiter plate test developed by Stepanovic et al. [20]. Cell suspensions of P. aeruginosa, E. coli and binary species suspension (50\% of each) were diluted in TSB to obtain a final concentration approximately $1 \times 10^{7} \mathrm{cfu} / \mathrm{ml}$. Afterwards, $200 \mu \mathrm{l} /$ well of the bacterial suspension were transferred to sterile 96-well flat-bottom tissue culture plates (Orange Scientific, Braine-l'Alleud, Belgium). All the plates were incubated aerobically on a horizontal shaker $(120 \mathrm{rpm})$, at $37^{\circ} \mathrm{C}$, during $24 \mathrm{~h}$ for biofilm development.

After $24 \mathrm{~h}$ of biofilm growth, the supernatant containing planktonic cells and media was removed. The wells were re-filed with fresh TSB or TSB containing BC in a final concentration of $0.9 \mathrm{mM}$ to mimic external $\mathrm{BC}$ chemical pressure in order to induce the adaptation of the biofilm-embedded cells. This process of supernatant removal and media filling was repeated for five subsequent days, every $24 \mathrm{~h}$. The six day-old biofilms 
formed in TSB supplemented with BC are hereafter referred as adapted biofilms while the biofilms formed only in TSB will be referred as normal biofilms.

\section{Biofilm treatment with BC}

After being developed in the absence and presence of $\mathrm{BC}$ for $6 \mathrm{~d}$ (during the adaptation process), biofilms were subjected subsequently to sudden attack with the same antimicrobial product. For that, the liquid content of each well was removed and washed once with $200 \mu \mathrm{l}$ of UP sterilized water, being the well-attached biofilms (biofilms formed by P. aeruginosa and E. coli in the inner surfaces of each well of the microtiter plates) subsequently treated with $200 \mu \mathrm{l}$ of $1.0 \mathrm{mM}$ of $\mathrm{BC}$ for $30 \mathrm{~min}$. This procedure had the major purpose of eliminating more susceptible and outward biofilm-cells. Non-treated wells were filled with $200 \mu$ l of UP sterilized water for the same period of time. After that, the content of each well was removed and biofilms were washed twice with $200 \mu \mathrm{l}$ with UP sterilized water and reserved for subsequent analysis.

Bacterial suspensions of the single and binary P. aeruginosa and E. coli non- and adapted biofilms to be used in protein and polysaccharide quantification and cfu determination were prepared as described hereafter. Two-hundred microliters of UP sterilized water were added to each well, being the wells-attached biofilms removed by ultrasonic bath in a Sonicor SC-52 (Sonicor Instruments, Copaique, NY, USA) operating at $50 \mathrm{kHz}$, during $6 \mathrm{~min}$ (these parameters were previously optimized in order to promote the complete removal of all the biofilm-attached cells without lysis). Afterwards, the single and mixed bacterial suspensions of each 5 wells per condition were collected, gently vortexed for 2 min [22-24] to disrupt possible cell aggregates, and reserved for later analysis.

\section{Biofilm analyses}

Biofilm cell enumeration

In order to determine the number of cfu, the untreated and $\mathrm{BC}$ treated axenic and binary biofilm suspensions removed by sonication were serially diluted. After plating the serial dilution on TSA, plates were incubated at $37^{\circ} \mathrm{C}$ in an aerobic incubator for $24 \mathrm{~h}$ prior to enumeration.

\section{Biofilm mass determination}

Biomass of P. aeruginosa, E. coli and binary biofilms was quantified by crystal violet (CV) staining method adapted from Stepanovic et al. [20]. For that, the plates containing the normal and adapted biofilms were left to air dry for $30 \mathrm{~min}$, and $200 \mu \mathrm{l}$ of $98 \%$ methanol were transferred to each well in order to fix the remaining attached bacteria, for $15 \mathrm{~min}$. Afterwards, the plates were emptied and left to air dry again. The fixed bacteria were stained with $200 \mu \mathrm{l}$ of $1 \%$ (w/v) CV (Gram colour-staining set for microscopy; Merck) per well, for $5 \mathrm{~min}$. After the staining step, the plates were washed with running tap water and air dried for approximately $20 \mathrm{~min}$ and, at last, $200 \mu \mathrm{l}$ of $33 \%(\mathrm{v} / \mathrm{v})$ of glacial acetic acid (Merck) were added to each well in order to resolubilise the CV bound to the adherent bacteria. The quantitative analysis of biofilm production was performed through the measurement of optical density at $570 \mathrm{~nm}$ $\left(\mathrm{OD}_{570}\right)$ in each well using a microtiter plate reader being the biofilm mass presented as $\mathrm{OD}_{570}$. Control experiments to avoid false results were also performed in order to determine whether the tested media and the plate material could adsorb CV and interfere with biomass quantification. When the optical density was higher than 1.0 the sample was diluted with $33 \%(\mathrm{v} / \mathrm{v})$ of glacial acetic acid. For each condition tested, 16 different wells were used to perform biofilm analysis and the experiment was performed with three independent assays.

\section{Biofilm activity determination}

Biofilm activity determination was evaluated with 2,3-bis (2-methoxy-4-nitro-5-sulfophenyl)-2H-tetrazolium-5-carboxanilide sodium salt (XTT) colorimetric method as described by Stevens and Olsen [25], with some modifications.

Bacteria, when metabolically active, reduce XTT to a water-soluble orange formazan that diffuses from the cells and thus does not require solvent extract prior to its quantification. Since the formazan product is water soluble, it is easily quantified by spectrophotometry analysis. Therefore, the quantity of formazan produced is used as a measure of the total respiratory activity of the bacteria. This latter point is important in biofilm research because the XTT assay allows the study of intact biofilms without disruption biofilm structure [26].

After biofilm growth and washing procedures, $200 \mu \mathrm{l}$ of a combined solution of XTT (Sigma) and phenazine methosulfate (PMS) (Sigma) were added to each well in order to obtain a final concentration of $150 \mu \mathrm{g} / \mathrm{ml}$ of XTT and $10 \mu \mathrm{g} / \mathrm{ml}$ of PMS. After that, plates were incubated at $37^{\circ} \mathrm{C}$ for $3 \mathrm{~h}$, at $120 \mathrm{rpm}$, in the dark. Biofilm activity was determined through the measurement of the optical density at $490 \mathrm{~nm}\left(\mathrm{OD}_{490}\right)$ in each well using a microtiter plate reader, being biofilm activity presented as $\mathrm{OD}_{490}$. Control tests, using culture medium and empty wells, were also carried out in order to avoid 
misleading results. For each condition tested, 16 different wells were used to perform biofilm analysis and the experiment was performed with three independent assays.

\section{Proteins and polysaccharide quantification}

The total content of proteins of the single and mixed suspensions from normal and adapted biofilms, untreated and treated with $\mathrm{BC}$, was determined using the BCA Protein Assay Kit (Pierce, Bonn, Germany), with bovine serum albumin as a protein standard, and the optical density (OD) values recorded at $740 \mathrm{~nm}$. The total polysaccharides content was determined by the phenol-sulphuric acid method described by Dubois et al. [27] with glucose as standard, and the OD values were recorded at $490 \mathrm{~nm}$. This biochemical characterization was performed in three independent experiments.

\section{Scanning electron microscopy (SEM) observations}

Prior to SEM observations, the wells-attached washed biofilms were gradually dehydrated in an absolute ethanol (Merck) series (15 min each in 10, 25, 40, 50, 70, $80,90$ and $100 \% \mathrm{v} / \mathrm{v})$. The wells-attached normal and adapted biofilms were kept in a dessicator until the walls of the wells were cut and coated with gold. The examination of the surface structural conformation of the biofilms was performed with a Leo scanning electron microscope (Cambridge). SEM observations were documented through the acquisition of representative microphotographs.

\section{Statistical analysis}

Statistical analysis was performed using GraphPad Prism, version 4.00 software for Macintosh. Normality of data distribution was tested by the KolmogorovSmirnov method. Statistical significance values of the groups' means of biofilm mass, biofilm activity, cell number and protein and polysaccharide content were evaluated using a one-way analysis of variance. Subsequent comparisons were performed using Tukey's posthoc test. The statistical analyses performed were considered significant when $p<0.05$.

\section{Results}

\section{Determination of MIC and MBC}

The MIC and MBC of planktonic P. aeruginosa and E. coli are shown in Table 1. P. aeruginosa revealed the highest MIC and MBC values when compared with those obtained for E. coli. To promote a selective BC pressure on planktonic growth of both strains, a BC concentration
Table 1. Minimum inhibitory concentration (MIC) and minimum bactericidal concentration (MBC) values of $\mathrm{BC}$ against Pseudomonas aeruginosa and Escherichia coli.

\begin{tabular}{lll}
\hline & MIC (mM) & MBC (mM) \\
\hline P. aeruginosa & 0.450 & 0.900 \\
E. coli & 0.225 & 0.225 \\
\hline
\end{tabular}

of $0.9 \mathrm{mM}$ was chosen for the biofilm adaptation process.

\section{Biofilm analyses}

Biofilm mass

In order to determine the biofilm formation ability of P. aeruginosa, E. coli and its binary combination, in the absence (normal biofilms) and in the presence of $0.9 \mathrm{mM}$ of $\mathrm{BC}$ (adapted biofilms), the total biomass was determined. Fig. $1 \mathrm{~A}$ shows that the six day-old biofilms formed by single species and by the combination of both species in TSB have similar biomass values. The posterior treatment with $1.0 \mathrm{mM}$ of $\mathrm{BC}$ did not alter the biofilm mass accumulated on the surfaces $(p>0.05)$.

It was also observed that both single and binary six day-old adapted biofilms have clearly more biomass $(p<0.001)$, about five times more, than the normal biofilms formed in the absence of BC. Fig. 1A also reveals that E. coli adapted biofilms have more mass than those of $P$. aeruginosa $(p<0.01)$ and than binary biofilms $(p<0.05)$. Furthermore, posterior BC treatment seems to reduce the mass of $P$. aeruginosa adapted biofilms $(p<0.05)$ and to increase the biomass of the binary biofilms $(p<0.001)$.

\section{Biofilm activity}

The metabolic activity of the viable biofilm-entrapped cells is presented in Fig. 1B. P. aeruginosa cells of normal biofilms revealed an increased activity in comparison with that of adapted biofilm-entrapped bacteria $(p<0.001)$. Data also show that both single and binary adapted biofilms have less activity than those formed in the absence of $\mathrm{BC}(p<0.01)$. Among the adapted biofilms, binary biofilms present the highest cell activity and $P$. aeruginosa biofilms the lowest $(p<0.001)$. Concerning biofilm treatment with $\mathrm{BC}$, the activity of the biofilm-associated cells was significantly reduced $(p<0.001)$ in normal biofilms. Furthermore the six-days old $P$. aeruginosa biofilms developed in the presence of $\mathrm{BC}$, when challenged with the same product, revealed even more activity than the biofilms without treatment $(p<0.001)$. Adapted binary biofilms and E. coli biofilms did not exhibit major changes in their activity upon QAC treatment $(p>0.05)$. 

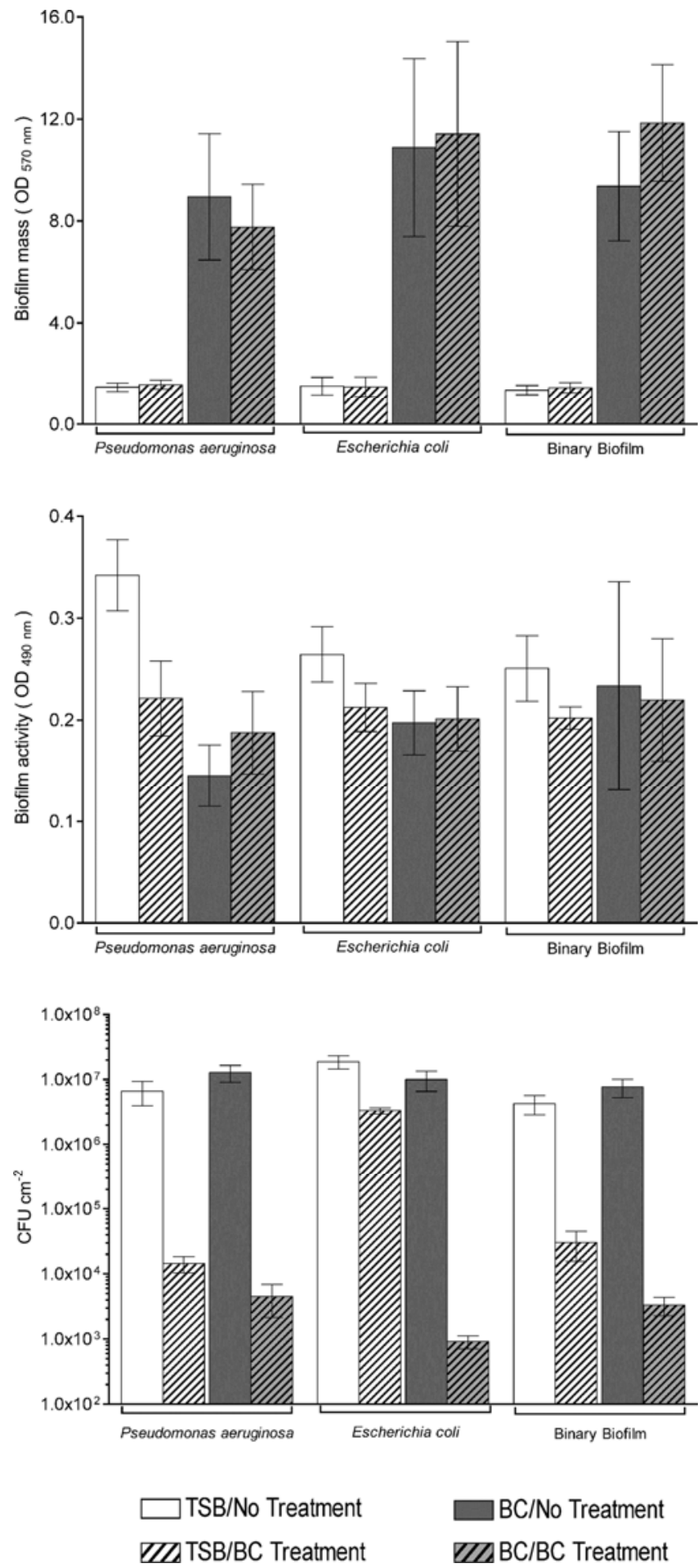

Figure 1. Biomass $\left(\mathrm{OD}_{570 \mathrm{~mm}}\right)(\mathrm{A})$, metabolic activity $\left(\mathrm{OD}_{490 \mathrm{~mm}}\right)(\mathrm{B})$ and number of cultivable cells $(\mathrm{C})$ of single and binary six day-old $P$. aeruginosa and $E$. coli biofilms developed in TSB (white bars) and TSB supplemented with $0.9 \mathrm{mM}$ of BC (grey bars). Biofilms were after treated with $1.0 \mathrm{mM} \mathrm{BC}$ (striped bars), non-treated biofilms (solid bars). Bars represent the average of 3 independent repeats $\pm S D$.

\section{Biofilm-entrapped cells}

Concerning the number of biofilm-associated cells, after six days of biofilm growth (Fig. 1C), it was observed that the adaptation to $\mathrm{BC}$, both for single and binary biofilms, seemed not to have influence on the number of total cells. In fact, the total number of cells entrapped in the biofilms was similar (approximately $10^{7} \mathrm{cfu} / \mathrm{cm}^{2}$ ), whether adapted or not to BC.

On the other hand, BC treatment of single P. aeruginosa and binary normal biofilms led to a $3 \log$ reduction $(p<0.001)$ in cell number whereas E. coli biofilm-entrapped cells just suffered a reduction of about $1 \log$.

The effect of $\mathrm{BC}$ treatment on adapted biofilms was similar to the one observed in the normal biofilms as it also led to a decrease of about $3 \log (p<0.001)$ in the number of biofilm-entrapped cells.

Biochemical biofilm characterization

As the data showed that adaptation to $\mathrm{BC}$ seems to promote an increase in biomass values (Fig. 1A), it was considered pertinent to inspect the biochemical features of all biofilms.

According to Fig. 2, P. aeruginosa normal biofilms exhibit more protein content when compared to the other biofilms (E. coli and binary) $(p<0.001)$. However, when the biofilms were adapted to BC, E. coli biofilms were those that revealed the highest protein content $(p<0.001)$. The presence of BC during biofilm development leads to biofilms characterized by 4-fold higher protein content, for P. aeruginosa and binary biofilms, and 8-fold higher for E. coli biofilms.

After BC challenge, normal biofilms did not show great variability in their protein content. Concerning adapted biofilms, the treatment with $1.0 \mathrm{mM}$ of $\mathrm{BC}$ promoted a reduction of about $50 \%$ of the protein content for P. aeruginosa and binary biofilms while for E. coli biofilms this reduction was just about $20 \%$.

The amount of polysaccharides in normal biofilms was similar for all the strains. The presence of BC during biofilm development led to a significant increase of polysaccharide content, being about 10 times superior in $P$. aeruginosa and binary biofilms, and about 13 times superior in the case of E. coli.

The $\mathrm{BC}$ treatment promoted an augment in polysaccharide content of $P$. aeruginosa biofilms $(p<0.01)$ while no significant change was observed for E. coli and binary biofilms $(p>0.05)$, when developed only in TSB.

The $\mathrm{BC}$ challenge after biofilm adaptation to the same product promoted a significant decrease in the polysaccharide content, similar to that obtained for protein content. 

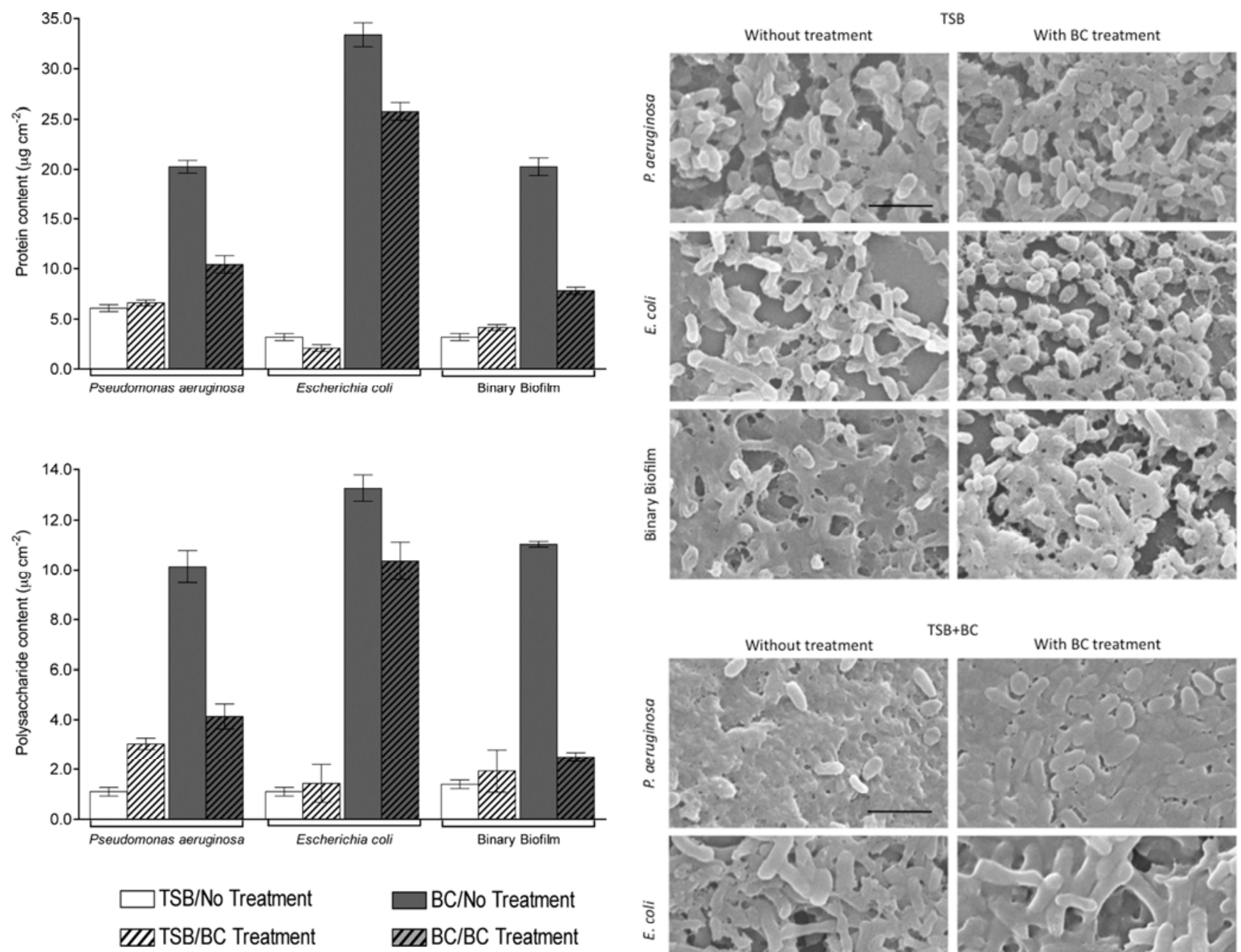

Figure 2. Biochemical biofilm characterization. Values of protein (A) and polysaccharide (B) content for of single and binary six dayold $P$. aeruginosa and $E$. coli biofilms developed in TSB (white bars) and TSB supplemented with $0.9 \mathrm{mM}$ of $\mathrm{BC}$ (grey bars). Biofilms were after treated with $1.0 \mathrm{mM} \mathrm{BC}$ (striped bars), non-treated biofilms (solid bars). Bars represent the average of 3 independent repeats $\pm S D$.

\section{Scanning electron microscopy observations}

The influence of $\mathrm{BC}$, on biofilm superficial structure and morphology was assessed by SEM inspection (Fig. 3).

SEM observations revealed a morphological alteration induced by the presence of $\mathrm{BC}$ during biofilm formation. The images of the adapted biofilms surface seem to indicate a larger amount of EPS, especially for P. aeruginosa and E. coli single-species biofilm.

The $\mathrm{BC}$ treatment after biofilm formation has different effects depending on the biofilms being adapted to $\mathrm{BC}$ or not. For biofilms formed in TSB, BC treatment

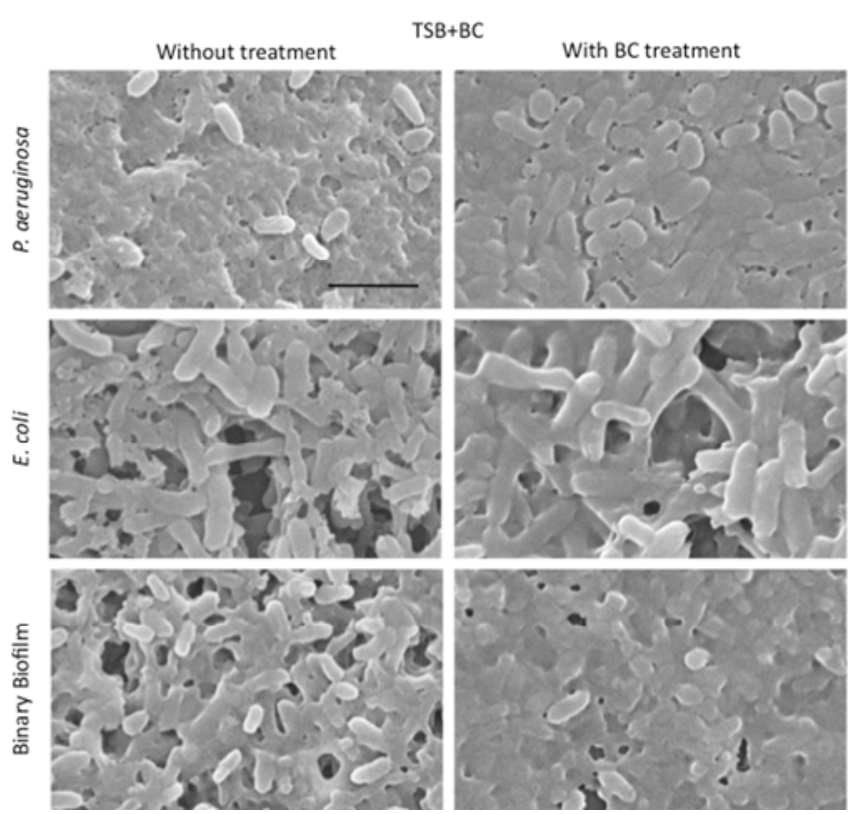

Figure 3. Scanning electron microscopy of single and binary six day-old $P$. aeruginosa and $E$. coli biofilms developed in TSB and TSB supplemented with $0.9 \mathrm{mM}$ of $\mathrm{BC}(\mathrm{TSB}+\mathrm{BC})$ without and with $1.0 \mathrm{mM} \mathrm{BC}$ treatment. $X 10000$ magnification, bar $=2.0 \mu \mathrm{m}$.

appears to cause some damages in the EPS matrix protecting biofilms. This matrix disruption is well noticed in E. coli and binary biofilms. For adapted biofilms, the images suggest that the subsequent $\mathrm{BC}$ challenge strengthens the existing matrix, giving the biofilm-entrapped cells an interconnected structure. 


\section{Discussion}

P. aeruginosa and E. coli are two human pathogens and commensal organisms often related with foreign body infections, mainly due to their ability to form biofilms. It is widely held that a biofilm represents a highly selective micro-niche where pathogens may also have high mutation rates or easily exchange genetic material, thus facilitating the development of antimicrobial drug resistance [36].

The continuous and, sometimes, inappropriate use of antimicrobials in several settings (households, hospitals and other institutions), together with the increased use of antibiotics to cure everyday diseases has been on the basis of selection of resistant bacteria. Moreover, the well-known biofilm microniche properties and their intrinsic resistance to antimicrobial products due to their specific features, namely, EPS matrix protective barrier, nutrient and oxygen gradients, cell-cell signalling, persister cells and genetic diversity, play a key-role in this easily acquired resistance.

The planktonic bacterial adaptation to $\mathrm{BC}$ is a well documented subject [37-40] and, recently, there have been some studies reporting biofilm adaptation to $\mathrm{BC}$ sub-MIC [16, 41-44]. From the analyses of the latter studies, it was observed that the BC concentrations used for biofilm adaptation are not always the same, albeit being always lower than the MIC concentration determined. The adaptation method used to induce an adaptive tolerance of the biofilm-entrapped cells is not standardized, varying among authors, microorganisms and studies.

In the present work, the adaptation of the P. aeruginosa and E. coli bacteria embedded in sessile life-style was attained at a $\mathrm{BC}$ concentration of $0.9 \mathrm{mM}$. It was not our objective to characterize which phenomenon (recalcitrance or resistance) was involved, but to study the biofilm phenotype after exposure to chemical stress conditions. The $\mathrm{BC}$ concentration used is higher than the ones used to adapt Salmonela $(0.29 \mathrm{mM})[16,41]$ within biofilms and Listeria planktonic cells $(0.012 \mathrm{mM})$ [44]. Despite being the highest MBC determined for the most resistant strain ( $P$. aeruginosa), the concentration of $0.9 \mathrm{mM}$ was used to promote the $\mathrm{BC}$ pressure. Results showed that the presence of this $\mathrm{BC}$ concentration in the liquid environment surrounding biofilms did not impair their growth or caused cell death within the biofilms, since no reduction of the absorbance related with biomass (Fig. 2A) or decrease in cell number (Fig. 2C) was observed. These data are not surprising since it is widely accepted that cells entrapped in biofilms easily gain tolerance to antimicrobials. Nor- mally, this insusceptibility is overcome with the use of supra inhibitory concentrations (supra-MIC) to ensure sanitation. The unexpected result of this study is the significant increase of biofilm mass due to $\mathrm{BC}$ pressure (5-fold higher) regardless the strain or the number of strains that generate the biofilm (Fig. 1A). These results show how the inappropriate use of an antimicrobial can favour bacteria attachment and biofilm formation, instead of eradicating biofilms and kill microorganisms. In fact, in real situations, this can be a genuine concern as it can happen in clinical settings or apparatus, where the use of antimicrobials is unavoidable, as reported by Lee et al. [45] in liquid reservoirs where antimicrobials are kept.

The adapted biofilms showed an increase in biofilm biomass (Fig. 1) that was corroborated by its biochemical characterization (Fig. 2) since the biofilms formed in TSB supplemented with BC revealed a protein and polysaccharide content higher than the normal biofilms. Since extracellular polysaccharides and proteins are two of the major matrix components [46, 47], our data suggest that adapted biofilms present a well-defined and strong EPS matrix.

SEM pictures (Fig. 3) confirmed this feature as it was well noticed a denser outward EPS matrix evolving bacteria, being this especially evident in $P$. aeruginosa and E. coli single biofilms. Based on these characteristics, it can be speculated that the presence of $\mathrm{BC}$ during biofilm formation may give rise to adapted biofilms with a stronger and cohesive structural conformation. EPS are a complex and extremely important component of biofilms, providing architectural structure and mechanical stability to the attached bacteria [48]. From the point of view of disinfection, this feature can represent an additional nuisance since biofilm matrix acts as shield to external stresses, limiting, for instance, the diffusion of antimicrobials. According to Branda et al. [49], small changes in the environmental conditions may promote dramatic changes in biofilm architectures being the environment where biofilms are developed responsible for the matrix composition. So, it can be concluded that the presence of $\mathrm{BC}$ in the liquid interface surrounding the single and binary biofilms during its establishment can be the environmental factor that changes biofilm surface structure, making the biofilm-associated bacteria possibly more tolerant to antimicrobials.

In attempting to expand the understanding of biofilm cell physiology, the response of P. aeruginosa and E. coli entrapped in single and binary biofilms to BC treatment was examined. The $\mathrm{BC}$ concentration used for the subsequent attack of the established 6-days-old 
biofilms was similar to that used for biofilm adaptation due to the fact $0.9 \mathrm{mM}$ is already a high concentration when compared with the normally in-use BC concentration in cleaning products $[1.0 \%(\mathrm{w} / \mathrm{v})][21]$.

Lindsay et al. referred that the growth of Pseudomonas spp with other strains might be beneficial as the EPS produced by Pseudomonas spp may confer some protection to the binary biofilm and thus protect it against sanitizer treatment $[17,50]$. In the present study, the data did not corroborate that study, as the binary growth of biofilm does not seem to give any advantage or disadvantage concerning the response to the presence of $\mathrm{BC}$ during biofilm development or the $\mathrm{BC}$ challenge.

The E. coli biofilms formed in normal conditions, i.e. in the absence of $\mathrm{BC}$, seem to show less sensitivity to $\mathrm{BC}$ attack (Fig. 1C) presenting also more unwavering protein and polysaccharide content (Fig. 2). Actually, a careful observation of the values obtained with the biochemical characterization of E. coli biofilms reveals that after $\mathrm{BC}$ treatment there is just a small reduction in these contents. In this case, the EPS matrix seems to be a crucial structural parameter for E. coli biofilm stability and architecture providing a refuge for bacterial community [49]. The limited effectiveness of antimicrobials to eradicate the microorganisms of biofilm infections may be related to non-mutational or physiological conditions that allow survival, like those related to stationary-phase physiology, low oxygen and nutrient penetration, low penetration of antimicrobials or antibiotics and slow growth. This particular phenotype confers biofilms tolerance or recalcitrance [31-33].

$P$. aeruginosa is known to produce mainly alginate during EPS excretion $[48,51]$ and there are studies referring alginate overproduction during nitrogen limitation [52] and after P. aeruginosa membrane perturbation induced by ethanol [53]. E. coli matrix is composed mainly of colanic acid [5, 6, 54-57]. Pringent-Combaret et al. [57] reported that the copious amount of appendages present at the cell surface (such as curli in E. coli and type IV pili in P.aeruginosa) and the various exopolymers excreted by bacteria can also concentrate ionic molecules from the biofilm phase as the biofilm develops. These different cell appendages and matrix main components together with the possible different response of each strain to $\mathrm{BC}$ stress can be the reason for the different biofilm behaviour observed and it can also explain the ability of $\mathrm{BC}$ treatment to disrupt matrices.

The maintenance of the number of entrapped-cells of adapted biofilms (Fig. 1C) can be due to the protective effect of the cohesive matrix observed in SEM (Fig. 3). In this study, E. coli biofilm-entrapped cells probably have undergone some kind of phenotypic change due to the fact of being part of a biofilm. In fact, the entrappedcells of adapted biofilms appeared to be more sensitive to $\mathrm{BC}$ than the cells of normal biofilms. It can also be due to the difficulty of detecting persister cells by culturability methods [31]. According to a study of Mangalappalli-Illathu [41], the regrowth of Salmonella enterica serovar Enteritidis after BC exposure was due to a small percentage of survivor cells that, after BC stress relief, were able to recover and multiply, being these survivors the sign of the so called persistence and regrowth of biofilms.

When considering the antimicrobial effect of disinfectants, it is not merely the killing of bacteria that is of interest. Removal of biofilm from the surfaces is also important as residual sessile cells may facilitate rapid regrowth of new biofilms [58]. So, in conclusion, it appears that E. coli and P. aeruginosa entrapped in single and mixed biofilms may develop adaptive resistance to $\mathrm{BC}$, noticeable by the over secretion of matrix components during biofilm development in presence of that antimicrobial product. Overall results clearly point out that BC had poor antimicrobial efficacy against E. coli and $P$. aeruginosa biofilms development and control.

Knowing that the amount of matrix is one of the most important contributes to the virulence of biofilms, the use of $\mathrm{BC}$ as an antimicrobial agent should be avoided and special care should be taken when dealing with inappropriate doses of this antibacterial agent. The suitable concentration of antimicrobial should always be supported by experimental assays. Otherwise, biofilm establishment and bacteria virulence might be favoured, contributing, in this way, to the increased prevalence of surface contamination and biofilmassociated infections. The data of this study did not allow the determination of which phenomenon (phenotypic adaptation, genetic acquired resistance or both) was responsible for the adaptation of biofilms to sublethal QAC exposure. Therefore, future work will be required to unravel the mechanism(s) by which the biofilm-entrapped bacteria respond to environmental pressures. This can be achieved by the determination of genetic and proteomic regulation of EPS production under BC stress.

\section{Acknowledgements}

The financial support from IBB-CEB and Fundação para a Ciência e Tecnologia (FCT) and European Community fund FEDER, through Program COMPETE, in the ambit 
of the Project PTDC/SAUESA/64609/2006/FCOMP-010124-FEDER-00702 and Idalina Machado PhD Grant (SFRH/BD/31065/2006) and Susana Lopes PhD Grant (SFRH/BD/47613/2008) are gratefully acknowledged.

\section{Conflict of Interest Statement}

We declare that we have no proprietary, financial, professional or any other personal interest of any nature or any kind in any service, product or company that could influence opinions and positions presented in the manuscript.

\section{References}

[1] Kramer, A., Schwebke, I., Kampf, G., 2006. How long do nosocomial pathogens persist on inanimate surfaces? A systematic review. BMC Infect. Dis., 6, 130.

[2] Costerton, J.W., Stewart, P.S., Greenberg, E.P., 1999. Bacterial biofilms: A common cause of persistent infections. Science, 284, 1318-1322.

[3] Davies, D.G., Chakrabarty, A.M., Geesey, G.G., 1993. Exopolysaccharide production in biofilms: substratum activation of alginate gene expression by Pseudomonas aeruginosa. Appl. Environ. Microbiol., 59, 1181-1186.

[4] Mathee, K., Ciofu, O., Sternberg, C., Lindum, P.W. et al., 1999. Mucoid conversion of Pseudomonas aeruginosa by hydrogen peroxide: a mechanism for virulence activation in the cystic fibrosis lung. Microbiology, 145, 13491357.

[5] Danese, P.N., Pratt, L.A., Kolter, R., 2000. Exopolysaccharide production is required for development of Escherichia coli K-12 biofilm architecture. J. Bacteriol., 182, 3593-3596.

[6] Domka, J., Lee, J., Bansal, T., Wood, T.K., 2007. Temporal gene-expression in Escherichia coli K-12 biofilms. Environ. Microbiol., 9, 332-346.

[7] Walton, J., Hill, D., Protheroe, R., Nevill, A., Gibson, H., 2008. Investigation into the effect of detergents on disinfectant susceptibility of attached Escherichia coli and Listeria monocytogenes. J. Appl. Microbiol., 105, 309-315.

[8] Kawamura-Sato, K., Wachino, J., Kondo, T., Ito, H., Arakawa, Y., 2008. Reduction of disinfectant bactericidal activities in clinically isolated Acinetobacter species in the presence of organic material. J. Antimicrob. Chemother., 61, 568-576.

[9] Russell, A.D., 1999. Bacterial resistance to disinfectants: present knowledge and future problems. J. Hosp. Infect., 43, S57-S68.

[10] Chuanchuen, R., Beinlich, K., Hoang, T.T., Becher, A. et al., 2001. Cross-resistance between triclosan and antibiotics in Pseudomonas aeruginosa is mediated by multidrug efflux pumps: Exposure of a susceptible mutant strain to triclosan selects $\mathrm{nfxB}$ mutants overexpressing MexCDOprJ. Antimicrob. Agents Chemother., 45, 428-432.
[11] Mc Cay, P.H., Ocampo-Sosa, A.A., Fleming, G.T.A., 2010. Effect of subinhibitory concentrations of benzalkonium chloride on the competitiveness of Pseudomonas aeruginosa grown in continuous culture. Microbiology, 156, $30-38$.

[12] Sheldon, A.T., 2005. Antiseptic "resistance": Real or perceived threat? Clin. Infect. Dis., 40, 1650-1656.

[13] Donlan, R.M., Costerton, J.W., 2002. Biofilms: Survival mechanisms of clinically relevant microorganisms. Clin. Microbiol. Rev., 15, 167-193.

[14] Szomolay, B., Klapper, I., Dockery, J., Stewart, P.S., 2005. Adaptive responses to antimicrobial agents in biofilms. Environ. Microbiol., 7, 1186-1191.

[15] Resch, A., Rosenstein, R., Nerz, C., Gotz, F., 2005. Differential gene expression profiling of Staphylococcus aureus cultivated under biofilm and planktonic conditions. Appl. Environ. Microbiol., 71, 2663-2676.

[16] Mangalappalli-Illathu, A.K., Vidovic, S., Korber, D.R., 2008. Differential adaptive response and survival of Salmonella enterica serovar enteritidis planktonic and biofilm cells exposed to benzalkonium chloride. Antimicrob. Agents Chemother., 52, 3669-3680.

[17] Lindsay, D., Brozel, V.S., Mostert, J.F., von Holy, A., 2002. Differential efficacy of a chlorine dioxide-containing sanitizer against single species and binary biofilms of a dairy-associated Bacillus cereus and a Pseudomonas fluorescens isolate. J. Appl. Microbiol., 92, 352-361.

[18] Burmolle, M., Webb, J.S., Rao, D., Hansen, L.H. et al., 2006. Enhanced biofilm formation and increased resistance to antimicrobial agents and bacterial invasion are caused by synergistic interactions in multispecies biofilms. Appl. Environ. Microbiol., 72, 3916-3923.

[19] National Committee for Clinical Laboratory S., 2000. Methods for dilution of antimicrobial susceptibility tests for bacteria that grow aerobically, 5th ed. Approved standard M7-A5. National Committee for Clinical Laboratory Standards, Wayne, Pa.

[20] Stepanovic, S., Vukovic, D., Dakic, I., Savic, B., SvabicVlahovic, M., 2000. A modified microtiter-plate test for quantification of staphylococcal biofilm formation. J. Microbiol. Methods, 40, 175-179.

[21] Langsrud, S., Sundheim, G., 1997. Factors contributing to the survival of poultry associated Pseudomonas spp. exposed to a quaternary ammonium compound. J. Appl. Microbiol., 82, 705-712.

[22] Kim, J., Hahn, J.S., Franklin, M.J., Stewart, P.S., Yoon, J., 2008. Tolerance of dormant and active cells in Pseudomonas aeruginosa PA01 biofilm to antimicrobial agents. J. Antimicrob. Chemother., 63, 129-135.

[23] Bandara, H., Yau, J., Watt, R., Jin, L., Samaranayake, L., 2010. Pseudomonas aeruginosa inhibits in-vitro Candida biofilm development. Bmc Microbiology, 10, 125.

[24] Weber, M., French, C., Barnes, M., Siegele, D., McLean, R., 2010. A previously uncharacterized gene, yjfO (bsmA), influences Escherichia coli biofilm formation and stress response. Microbiology, 156, 139.

[25] Stevens, M.G., Olsen, S.C., 1993. Comparative analysis of using Mtt and Xtt in colorimetric assays for quantitating bovine neutrophil bactericidal activity. J. Immunol. Methods, 157, 225-231. 
[26] Kuhn, D.M., Balkis, M., Chandra, J., Mukherjee, P.K., Ghannoum, M.A., 2003. Uses and limitations of the XTT assay in studies of Candida growth and metabolism. J. Clin. Microbiol., 41, 506-508.

[27] DuBois, M., Gilles, K.A., Hamilton, J.K., Rebers, P.A., Smith F., 1956. Colorimetric method for determination of sugars and related substances. Anal. Chem., 28, 350-356.

[28] Muller, J., Stevens, A., Craig, J., Love, N., 2007. Transcriptome analysis reveals that multidrug efflux Ggnes are upregulated to protect Pseudomonas aeruginosa from pentachlorophenol stress. Appl. Environ. Microbiol., 73, 4550-4558.

[29] Orme, R., Douglas, C.W.I., Rimmer, S., Webb, M., 2006. Proteomic analysis of Escherichia coli biofilms reveals the overexpression of the outer membrane protein OmpA. Proteomics, 6, 4269-4277.

[30] Jarvis, W.R., Martone, W.J., 1992. Predominant pathogens in hospital infections. J. Antimicrob. Chemother., 29, 19-24.

[31] Lewis, K., 2005. Persister cells and the riddle of biofilm survival. Biochemistry (Mosc.), 70, 267-274.

[32] Fux, C.A., Costerton, J.W., Stewart, P.S., Stoodley, P., 2005. Survival strategies of infectious biofilms. Trends Microbiol., 13, 34-40.

[33] Dhar, N., McKinney, J.D., 2007. Microbial phenotypic heterogeneity and antibiotic tolerance. Curr. Opin. Microbiol., 10, 30-38.

[34] Moore, L.E., Ledder, R.G., Gilbert, P., McBain, A.J., 2008. In vitro study of the effect of cationic biocides on bacterial population dynamics and susceptibility. Appl. Environ. Microbiol., 74, 4825-4834.

[35] Kussell, E., Kishony, R., Balaban, N.Q., Leibler, S., 2005. Bacterial persistence: a model of survival in changing environments. Genetics, 169, 1807-1814.

[36] Parsek, M.R., Singh, P.K., 2003. Bacterial biofilms: an emerging link to disease pathogenesis. Annu. Rev. Microbiol., 57, 677-701.

[37] Loughlin, M.F., Jones, M.V., Lambert, P.A., 2002. Pseudomonas aeruginosa cells adapted to benzalkonium chloride show resistance to other membrane-active agents but not to clinically relevant antibiotics. J. Antimicrob. Chemother., 49, 631-639.

[38] Bore, E., Hebraud, M., Chafsey, I., Chambon, C. et al., 2007. Adapted tolerance to benzalkonium chloride in Escherichia coli K-12 studied by transcriptome and proteome analyses. Microbiology, 153, 935-946.

[39] Joynson, J.A., Forbes, B., Lambert, R.J.W., 2002. Adaptive resistance to benzalkonium chloride, amikacin and tobramycin: the effect on susceptibility to other antimicrobials. J. Appl. Microbiol., 93, 96-107.

[40] Adair, F.W., Liauw, H.L., Geftic, S.G., Gelzer, J., 1975. Reduced virulence of Pseudomonas aeruginosa grown in the presence of benzalkonium chloride. J. Clin. Microbiol., 1, 175-179.

[41] Mangalappalli-Illathu, A.K., Korber, D.R., 2006. Adaptive resistance and differential protein expression of Salmonella enterica serovar Enteritidis biofilms exposed to benzalkonium chloride. Antimicrob. Agents Chemother., 50, 3588-3596.

[42] Smith, K., Hunter, I.S., 2008. Efficacy of common hospital biocides with biofilms of multi-drug resistant clinical isolates. J. Med. Microbiol., 57, 966-973.
[43] Campanac, C., Pineau, L., Payard, A., Baziard-Mouysset, G., Roques, C., 2002. Interactions between biocide cationic agents and bacterial biofilms Antimicrob. Agents Chemother., 46, 1469-1474.

[44] Romanova, N.A., Wolffs, P.F.G., Brovko, L.Y., Griffiths, M.W., 2006. Role of efflux pumps in adaptation and resistance of Listeria monocytogenes to benzalkonium chloride. Appl. Environ. Microbiol., 72, 3498-3503.

[45] Lee, C.S., Lee, H.B., Cho, Y.G., Park, J.H., Lee, H.S., 2008. Hospital-acquired Burkholderia cepacia infection related to contaminated benzalkonium chloride. J. Hosp. Infect., 68, 280-282.

[46] Ma, L., Conover, M., Lu, H., Parsek, M.R. et al., 2009. Assembly and development of the Pseudomonas aeruginosa biofilm matrix. PLoS Pathog., 5, e1000354.

[47] Flemming, H.C., Neu, T.R., Wozniak, D.J., 2007. The EPS matrix: the "house of biofilm cells". J. Bacteriol., 189, $7945-7947$.

[48] Allison, D.G., 2003. The biofilm matrix. Biofouling, 19, 139-150.

[49] Branda, S.S., Vik, A., Friedman, L., Kolter, R., 2005. Biofilms: the matrix revisited. Trends Microbiol., 13, 2026.

[50] Pereira, M.O., Vieira, M.J., 2001. Effects of the interactions between glutaraldehyde and the polymeric matrix on the efficacy of the biocide against Pseudomonas fluorescens biofilms. Biofouling, 17, 93-101.

[51] Costerton, J.W., Cheng, K.J., Geesey, G.G., Ladd, T.I. et al., 1987. Bacterial biofilms in nature and disease. Annu. Rev. Microbiol., 41, 435-464.

[52] DeVault, J.D., Berry, A., Misra, T.K., Darzins, A., Chakrabarty, A.M., 1989. Environmental sensory signals and microbial pathogenesis: Pseudomonas aeruginosa infection in cystic fibrosis. Nat. Biotech., 7, 352-357.

[53] DeVault, J.D., Kimbara, K., Chakrabarty, A.M., 1990. Pulmonary dehydration and infection in cystic fibrosis: evidence that ethanol activates alginate gene expression and induction of mucoidy in Pseudomonas aeruginosa. Mol. Microbiol., 4, 737-745.

[54] Tschowri, N., Busse, S., Hengge, R., 2009. The BLUF-EAL protein YcgF acts as a direct anti-repressor in a blue-light response of Escherichia coli. Genes Dev., 23, 522-534.

[55] Sperandeo, P., Lau, F.K., Carpentieri, A., De Castro, C. et al., 2008. Functional analysis of the protein machinery required for transport of lipopolysaccharide to the outer membrane of Escherichia coli. J. Bacteriol., 190, 4460-4469.

[56] White, A.P., Gibson, D.L., Collinson, S.K., Banser, P.A., Kay, W.W., 2003. Extracellular polysaccharides associated with thin aggregative fimbriae of Salmonella enterica serovar enteritidis. J. Bacteriol., 185, 5398-5407.

[57] Prigent-Combaret, C., Vidal, O., Dorel, C., Lejeune, P., 1999. Abiotic surface sensing and biofilm-dependent regulation of gene expression in Escherichia coli. J. Bacteriol., 181, 5993-6002.

[58] Field, T.R., White, A., Elborn, J.S., Tunney, M.M., 2005. Effect of oxygen limitation on the in vitro antimicrobial susceptibility of clinical isolates of Pseudomonas aeruginosa grown planktonically and as biofilms. Eur. J. Clin. Microbiol. Infect. Dis., 24, 677-687. 